\title{
Star-shaped Hexa-peri-hexabenzocoronene "Heptamer": Synthesis and Self-assembly
}

\author{
Linjie Zhi, Jishan Wu, Klaus Müllen* \\ Max-Planck-Institute for Polymer Research, Ackermannweg 10, 55128, Mainz, Germany \\ muellen@mpip-mainz.mpg.de
}

\section{Supporting Information}

\section{Synthesis and characterization of key compounds}

Compound 6: $1.092 \mathrm{~g}$ (43.1 mmol) dried $\mathrm{Mg}$ was put into a dried $100 \mathrm{ml}$ flask. $45 \mathrm{ml}$ THF, $10.05 \mathrm{~g}$ (43.1 mmol) 11-bromo-1-undecene and small amount of iodine were added into the flask. The solution was stirred under argon at $45{ }^{\circ} \mathrm{C}$ for $4 \mathrm{~h}$. The solution was moved to another dry flask. $9.0 \mathrm{~g}$ (39.3 mmol) 1-bromo-4-(trimethylsily)benzene and 123 $\mathrm{mg}(0.15 \mathrm{mmol}) \mathrm{Pd}(\mathrm{dppf}) \mathrm{MeCl} 2$ were added into the solution, and reacted at $55{ }^{\circ} \mathrm{C}$ overnight. The mixture was treated with $10 \% \mathrm{HCl}$, extracted by $\mathrm{CH} 2 \mathrm{Cl} 2$, and dried with MgSO4. After columnar purification (silica gel, hexane), $10.05 \mathrm{~g}$ colorless oil was obtained (84\%). MS (FD, 8kV): m/z (\%) = $302.3(100 \%)[\mathrm{M}+]$ (calcd for C20H34Si = 302.58). ${ }^{1} \mathrm{H}$ NMR (250 MHz, C2D2Cl4): $\delta=7.34(\mathrm{~m}, 2 \mathrm{H}), 7.11(\mathrm{~d}, \mathrm{~J}=7.2 \mathrm{~Hz}, 2 \mathrm{H})$, $5.74(\mathrm{~m}, 1 \mathrm{H}), 4.88(\mathrm{~m}, 2 \mathrm{H}), 2.50(\mathrm{t}, \mathrm{J}=8.15 \mathrm{~Hz}, 2 \mathrm{H}), 1.95(\mathrm{~m}, 2 \mathrm{H}), 1.20(\mathrm{~s}, 14 \mathrm{H}), 0.18$ (s, 9H); ${ }^{13} \mathrm{C}$ NMR $(67.5 \mathrm{~Hz}, \mathrm{C} 2 \mathrm{D} 2 \mathrm{Cl} 4): \delta=143.79,139.59,137.25,133.70,128.23$, $114.57,36.33,34.16,31.71,30.09,29.87,29.52,29,29,0.61$. Anal. Calcd for C20H34Si(302.58): C, 79.32; H, 11.24. Found: C, 78.98; H, 11.02.

Compound 8: in a dry 100ml flask, $3.06 \mathrm{~g}(10.13 \mathrm{mmol})$ compound 6 was dissolved into 21.6ml 0.5M 9-BBN (10.81mmol) THF solution, which was stirred at room temperature overnight. Then, $3.4 \mathrm{ml} 3 \mathrm{M} \mathrm{NaOH}(10.13 \mathrm{mmol})$ solution was added. After 5 minutes, $1.135 \mathrm{~g}$ (3.38mmol) dibromodiphenylacetylenes and $137.8 \mathrm{mg} \quad(0.17 \mathrm{mmol})$ $\mathrm{Pd}(\mathrm{dppf}) \mathrm{MeCl} 2$ were put into the flask, and stirred at room temperature for $4 \mathrm{~h}$. The reaction mixture was poured into water and extracted by $\mathrm{CH} 2 \mathrm{Cl} 2$. The extracted solution was dried with MgSO4. After columnar purification (silica gel, PE:dichloromethane=10:1), 1.4g white solid was obtained (54\%). MS (FD, $8 \mathrm{kV}): \mathrm{m} / \mathrm{z}$ $(\%)=783.0(100 \%)[\mathrm{M}+]$ (calcd for C54H78Si2 = 783.40). ${ }^{1} \mathrm{H}$ NMR $(250 \mathrm{MHz}$, $\mathrm{CD} 2 \mathrm{Cl} 2): \delta=7.42(\mathrm{~d}, \mathrm{~J}=7.2 \mathrm{~Hz}, 8 \mathrm{H}), 7.16(\mathrm{~d}, \mathrm{~J}=7.2 \mathrm{~Hz}, 8 \mathrm{H}), 2.60(\mathrm{~m}, 8 \mathrm{H}), 1.59(\mathrm{~m}$, $8 \mathrm{H}), 1.29(\mathrm{~m}, 28 \mathrm{H}), 0.24(\mathrm{~s}, 18 \mathrm{H}) ;{ }^{13} \mathrm{C}$ NMR $(67.5 \mathrm{~Hz}, \mathrm{CD} 2 \mathrm{Cl} 2): \delta=144.16,143.95$, 137.41 , 133.68, 131.72, 128.91, 128.24, 120.88, 89.18, 36.29, 31.95, 31.69, 30.02, 29.97, 29.90, 29.86, 29.81, 29.66, 0.01. Anal. Calcd for C54H78Si2 (783.40): C, 82.72; H, 9.96. Found: C, 82.04; H, 10.12 .

Compound 9: 500.0mg (0.64mmol) compound 8 was dissolved in 100ml dioxane, and then degassed for $10 \mathrm{minutes} .22 .0 \mathrm{mg}(0.06 \mathrm{mmol})$ dicobaltoctacarbonyl was added under 
argon, and the reaction mixture was refluxed at $125^{\circ} \mathrm{C}$ for $22 \mathrm{~h}$. After evaporation of the solvent, chromatography (PE:dichloromethane $=5: 1$ ) was performed to get $405.0 \mathrm{mg}$ light yellow oil (81\%). MS (FD, $8 \mathrm{kV}): \mathrm{m} / \mathrm{z}(\%)=2350.1(100 \%)[\mathrm{M}+]$ (calcd for C162H234Si6 = 2350.19). ${ }^{1} \mathrm{H}$ NMR $(250 \mathrm{MHz}, \mathrm{C} 2 \mathrm{D} 2 \mathrm{Cl} 4): \delta=7.34(\mathrm{~d}, \mathrm{~J}=7.90 \mathrm{~Hz}$, $12 \mathrm{H}), 7.08(\mathrm{~d}, \mathrm{~J}=7.9 \mathrm{~Hz}, 12 \mathrm{H}), 6.54(\mathrm{~m}, 24 \mathrm{H}), 2.49(\mathrm{~m}, 12 \mathrm{H}), 2.25(\mathrm{~m}, 12 \mathrm{H}), 1.15(\mathrm{~m}$, $108 \mathrm{H}), 0.17(\mathrm{~s}, 54 \mathrm{H}) ;{ }^{13} \mathrm{C}$ NMR $(67.5 \mathrm{~Hz}, \mathrm{CD} 2 \mathrm{Cl} 2): \delta=145.11,141.74,140.80$, $139.73,138.38,134.67,132.70,129.22,127.83,37.29$, 36.69, 32.96, 32.71, 31.14, 31.07, 30.96, 30.91, 30.85, 30.31, 0.01. Anal. Calcd for C162H234Si6 (2350.19): C, 82.72; H, 9.96; Si, 7.32. Found: C, 83.12; H, 10.09 .

Compound 10: In a $25 \mathrm{ml}$ tube reactor, $460.0 \mathrm{mg}$ compound 9 was dissolved into $11 \mathrm{ml}$ fresh $\mathrm{CHCl} 3$. The solution was degassed with argon for 10 minutes. Then, at an ice bath, $1.17 \mathrm{ml} 1.0 \mathrm{M} \mathrm{ICl}$ solution was dropped into the reactor slowly under argon, and hold at room temperature for $30 \mathrm{~min}$. The reaction mixture was poured into $\mathrm{Na} 2 \mathrm{SO} 3$ solution, extracted by $\mathrm{CH} 2 \mathrm{Cl} 2$, washed with water several times, and dried by MgSO4. After columnar purification, 470.0mg white solid was obtained (90\%). MS (FD, 8kV): $\mathrm{m} / \mathrm{z}(\%)$ $=2672.2(100 \%)[\mathrm{M}+]$ (calcd for C144H180I6 = 2672.47). ${ }^{1} \mathrm{H}$ NMR $(250 \mathrm{MHz}$, $\mathrm{CD} 2 \mathrm{Cl} 2): \delta=7.57(\mathrm{~d}, \mathrm{~J}=8.20 \mathrm{~Hz}, 12 \mathrm{H}), 6.93(\mathrm{~d}, \mathrm{~J}=8.20 \mathrm{~Hz}, 12 \mathrm{H}), 6.66(\mathrm{~m}, 24 \mathrm{H})$, $2.53(\mathrm{~m}, 12 \mathrm{H}), 2.34(\mathrm{~m}, 12 \mathrm{H}), 1.23(\mathrm{~m}, 108 \mathrm{H}) ;{ }^{13} \mathrm{C} \mathrm{NMR}(67.5 \mathrm{~Hz}, \mathrm{CD} 2 \mathrm{Cl} 2): \delta=$ $143.15,140.71,139.77,138.70,137.56,131.68,130.97,126.81,90.62,35.75,31.68$, 30.08, 30.03, 29.98, 29.86, 29.60, 29.28. Anal. Calcd for C144H180I6 (2672.47): C, 64.66; H, 6.74; I, 28.60. Found: C, 63.86; H, 7.03.

Compound 11: A mixture of compound 10 (150.0mg, 0.056mmol), $\mathrm{Pd}\left(\mathrm{PPh}_{3}\right)_{4}$ (7.8mg, $0.0067 \mathrm{mmol})$, CuI ( $3.2 \mathrm{mg}, 0.017 \mathrm{mmol})$ in piperidine $(6 \mathrm{ml})$ was degassed by two "freezepump-thaw" cycles and then 4-n-dodecylphenylacetylene $(182.0 \mathrm{mg}, 0.674 \mathrm{mmol})$ was added. After stirring at $55^{\circ} \mathrm{C}$ for $20 \mathrm{~h}$, the reaction was quenched by $15 \% \mathrm{HCl}(10 \mathrm{ml})$ and extracted by dichloromethane. The organic phase was washed with water and dried MgSO4. After evaporation of the solvent, the residual was purified by column chromatography with petrol ether/dichloromethane 4:1 to yield compound 3 (130.0mg). yield: 66\%. MALDI-TOF MS: $\mathrm{m} / \mathrm{z}=3638\left(\sim[\mathrm{M}+\mathrm{Ag}]^{+}\right)$, calcd. 3527.76 for C264H354. ${ }^{1} \mathrm{H}$ NMR $(250 \mathrm{MHz}, \mathrm{CD} 2 \mathrm{Cl} 2): \delta=7.40(\mathrm{~d}, \mathrm{~J}=7.82 \mathrm{~Hz}, 24 \mathrm{H}), 7.15(\mathrm{~d}, \mathrm{~J}=8.30 \mathrm{~Hz}, 24 \mathrm{H})$, $6.66(\mathrm{~m}, 24 \mathrm{H}), 2.59(\mathrm{~m}, 24 \mathrm{H}), 2.34(\mathrm{~m}, 12 \mathrm{H}), 1.26(\mathrm{~m}, 224 \mathrm{H}), 0.88(\mathrm{~m}, 18 \mathrm{H}) ;{ }^{13} \mathrm{C}$ NMR $(67.5 \mathrm{~Hz}, \mathrm{CD} 2 \mathrm{Cl} 2): \delta=143.90,140.71,139.77,138.71,131.69,128.86$, 126.82, 120.87, 89.17, 36.21, 35.66, 32.31, 31.68, 30.05, 30.02, 29.97, 29.90, 29.86, 29.73, 29.66, 29.28, 23.07, 14.25. Anal. Calcd for C264H354 (3527.76): C, 89.80; H, 10.03. Found: C, 89.11; H, 10.21.

Compound 3: A mixture of ompound 11 (100.0mg, 0.0284mmol) and tetra(4dodecylphenyl)cyclopentadienone (360.0mg, $0.3408 \mathrm{mmol}$ ) in diphenylether $(2.5 \mathrm{ml})$ was heated at reflux for $44 \mathrm{~h}$ under an argon atmosphere. After cooling to room temperature ethanol $(50 \mathrm{ml})$ was added to the reaction mixture. The solvent was decanted and the residual oil was purified by column chromatography on silica gel with petroleum ether/dichloromethane 6:1 to afford $192.0 \mathrm{mg}$ product (69.8\%). MALDI-TOF MS: $\mathrm{m} / \mathrm{z}=$ $9818\left(\sim[\mathrm{M}+\mathrm{Ag}]^{+}\right)$, calcd. 9706.40 for C720H1050. ${ }^{1} \mathrm{H}$ NMR $(250 \mathrm{MHz}, \mathrm{CD} 2 \mathrm{Cl} 2): \delta=$ $6.65(\mathrm{~m}, 168 \mathrm{H}), 2.34(\mathrm{~m}, 84 \mathrm{H}), 1.26(\mathrm{~m}, 708 \mathrm{H}), 0.88(\mathrm{~m}, 90 \mathrm{H}) ;{ }^{13} \mathrm{C}$ NMR $(67.5 \mathrm{~Hz}$, 
CD2Cl2): $\delta=140.71,139.77,138.70,131.68,126.82,35.68,32.34,31.71,30.14$, 30.09, 29.93, 29.78, 29.31, 23.09, 14.27. Anal. Calcd for C720H1050 (9706.40): C, 89.09; H, 10.91. Found: C, 88.51; H, 11.12.

Compound 2: A solution of iron(III) chloride (94.0mg, 0.5802mmol) in nitromethane (1.5ml) was added dropwise to a stirred solution of compound $3(40.0 \mathrm{mg}, 0.00412 \mathrm{mmol})$ in dichloromethane $(22 \mathrm{ml})$. An argon steam was bubbled through the reaction mixture throughout the entire reaction. After stirring another 30 min the reaction was quenched with methnol $(50 \mathrm{ml})$. The precipitate was filtered, washed with methnol $(50 \mathrm{ml})$, and dried under vacuum. yield: 76\%. MALDI-TOF MS: $\mathrm{m} / \mathrm{z}=9624$ [ $\mathrm{M}^{+}$], calcd. 9621.73 for C720H966.

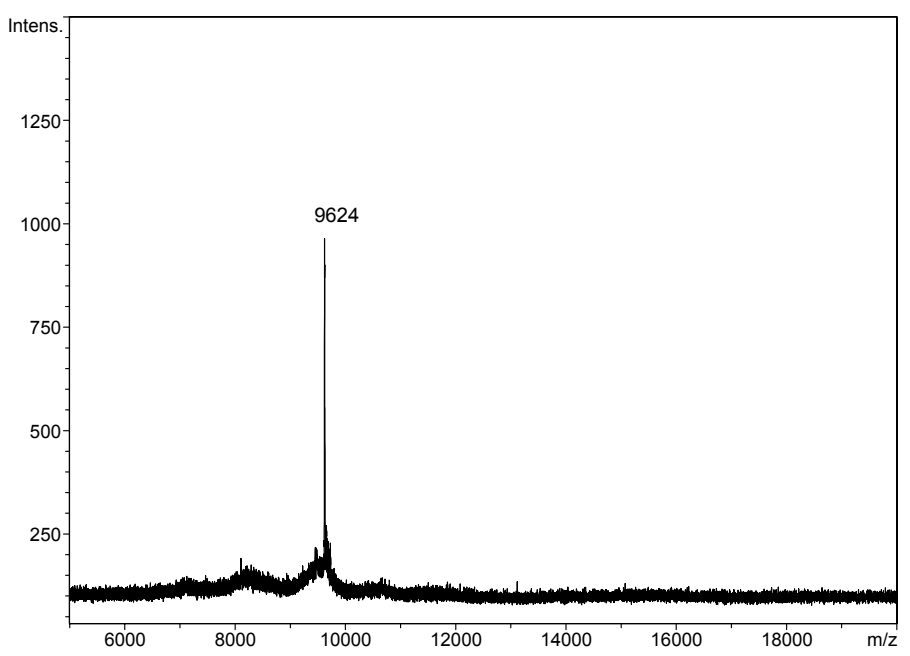

S-Figure 1: MALDI-TOF-MS of HBC heptamer 2

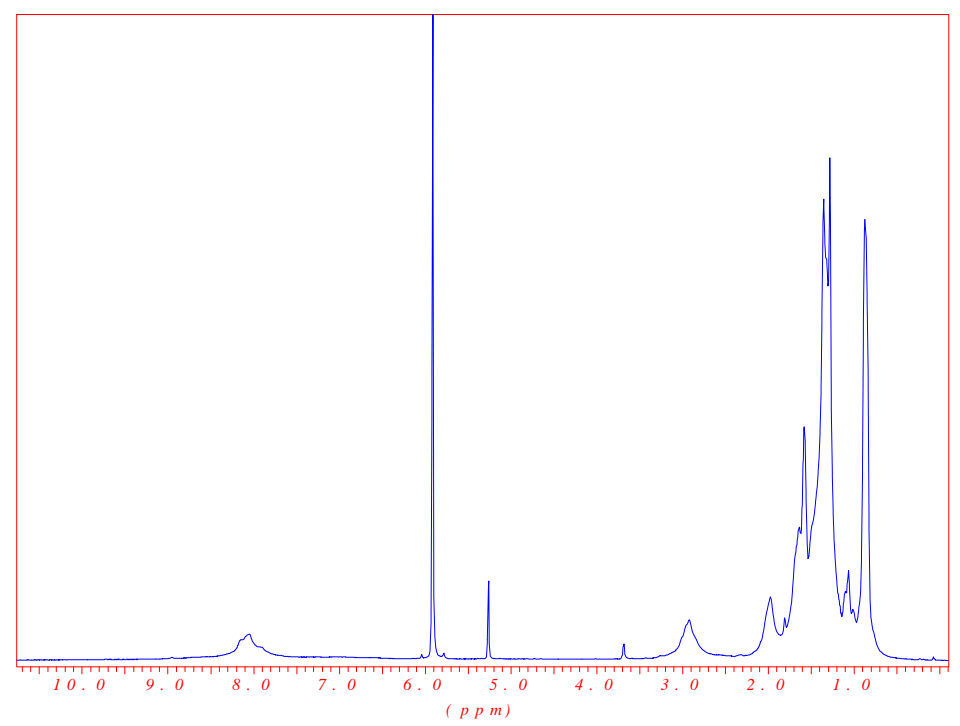

S-Figure 2: NMR spectra of compound 2 in $\mathrm{C} 2 \mathrm{D} 2 \mathrm{Cl} 4$ at $130{ }^{\circ} \mathrm{C}$ for two days 


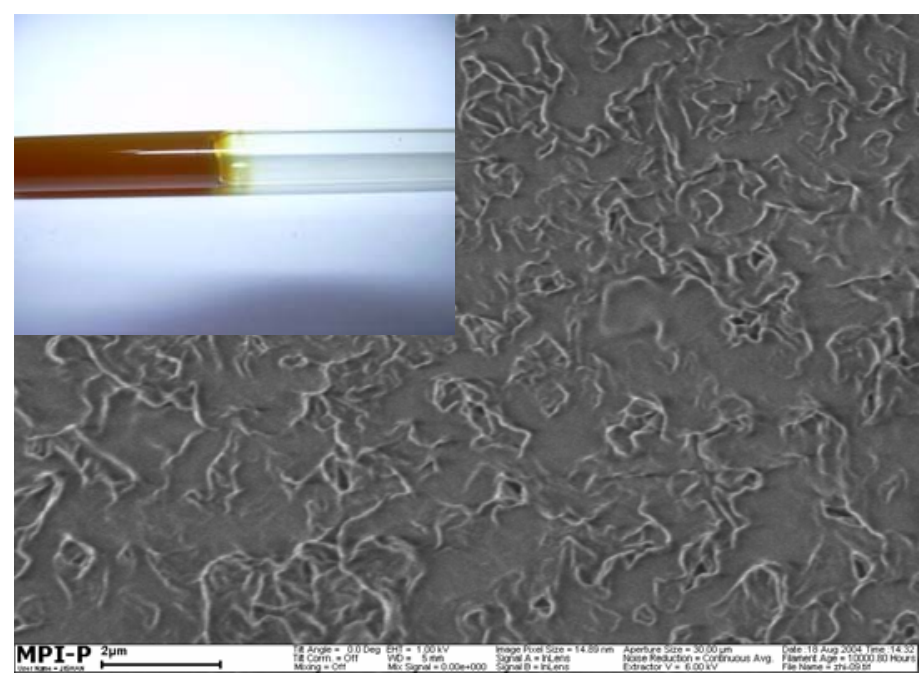

S-Figure 3: SEM image of the gel structure of HBC heptamer 2 formed in toluene 


\section{Table of Content}

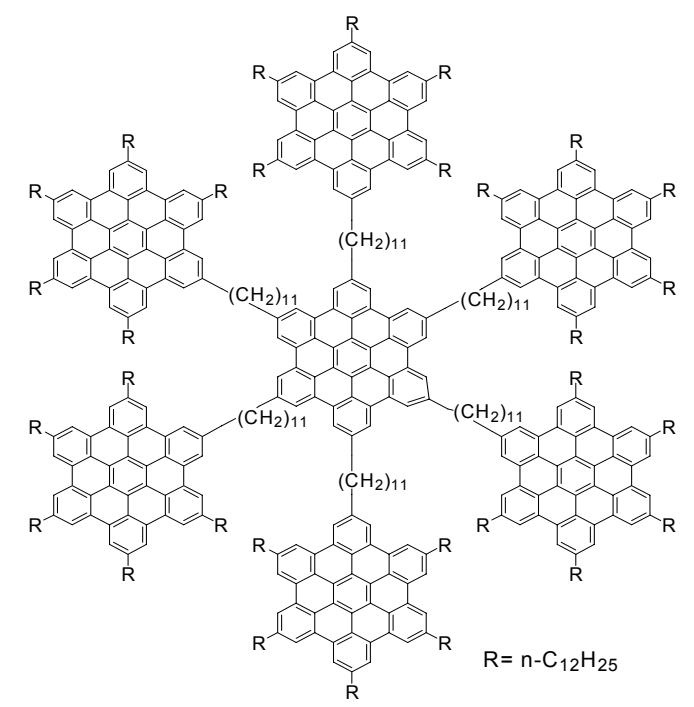

A star-shaped hexa-peri-hexabenzocoronene heptamer was prepared, which showed strong tendency to aggregate in solution and in the bulk states. Higher order was found in a high-temperature, columnar liquid crystalline phase due to the higher mobility of the molecules in comparison with low-temperature solid. In addition, physical gel formation was observed due to the presence of covalent intercolumnar interactions. 